\title{
On stability and relaxation techniques for partitioned fluid-structure interaction simulations
}

\author{
Johan Lorentzon ${ }^{1}$ and Johan Revstedt ${ }^{2}$ \\ ${ }^{1}$ Lunds Universitet Kemicentrum \\ ${ }^{2} \mathrm{LTH}$
}

December 7, 2021

\begin{abstract}
The stability of relaxation techniques has been studied for strongly coupled fluid-structure interaction (FSI) with application to a cantilever immersed in channel flow. The fluid is governed by Navier-Stokes equations for incompressible flow condition using turbulence modelling and the solid is governed by the equation of motion with compressible material modelling. The applied kinematic description is Lagrangian for the solid and Eulerian for the fluid. The coupling of the state solvers is achieved by the Arbitrary Lagrange-Euler procedure which involves a mesh motion solver and the FSI procedure is stabilised by relaxation. It is shown that the stability can be related to the frequency shift caused by FSI and they follow the same rate for the shape factor of the structure with an offset. This correlates well to theoretical results but also show that for given mesh resolution, all relaxations fail for sufficient high-frequency shift. We also propose a continuation technique to stabilise the solution near the instability region, which also improves the efficiency and can be integrated easily for the black-box FSI solution procedure.
\end{abstract}

\section{Hosted file}

manuscript.enginering-report.jljr-2021-12-06-elsevier-format-revised.pdf available at https: //authorea.com/users/449899/articles/548358-on-stability-and-relaxation-techniques-forpartitioned-fluid-structure-interaction-simulations

\section{Hosted file}

manuscript-jljr-2021-12-06-engineering-reports.tex available at https://authorea.com/users/ 449899/articles/548358-on-stability-and-relaxation-techniques-for-partitioned-fluidstructure-interaction-simulations

\section{Hosted file}

folders.zip available at https://authorea.com/users/449899/articles/548358-on-stability-andrelaxation-techniques-for-partitioned-fluid-structure-interaction-simulations 